\title{
Machine Learning Applications in Advanced Manufacturing Processes
}

\author{
DONNA POST GUILLEN (i) ${ }^{1,2}$ \\ 1.-Idaho National Laboratory, 955 MK Simpson Blvd., Idaho Falls, ID 83415, USA. \\ 2.-e-mail: Donna.Guillen@inl.gov
}

Machine learning holds tremendous promise for revolutionizing modern manufacturing, from conventional operations to new advanced manufacturing processes, such as additive manufacturing. This special topic focuses on reducing waste, energy usage. and carbon emissions, spurring innovation in materials development and production. Advances in digital manufacturing, process control, predictive maintenance, and automation can be realized by the integration of data analytics and validated models to ensure product quality, optimize operations, enhance productivity, and improve efficiency. Articles within this special topic present mathematically- and computationally-based applications to improve the efficiency of industrial manufacturing processes.

The papers featured in this special topic include "A Prediction Model of Blast Furnace Slag Viscosity Based on the Principal Component Analysis and KNearest Neighbor Regression" by Jiang et al., with a predictive model for the viscosity of blast furnace (BF) slag based on machine learning, principal component analysis, and k-nearest neighbor regression. Iron-making in a $\mathrm{BF}$ is one of the most complicated industrial processes, and viscosity has a large influence on the separation of $\mathrm{BF}$ molten iron and slag, the erosion of the hearth, and BF production. The detection of viscosity of BF slag has a large hysteresis, which confounds the

Donna Guillen served as the Guest Editor for the TMS Energy Committee and coordinated the topic Machine Learning Applications in Advanced Manufacturing Processes in this issue. Edward Herderick and Judy Schneider of the Additive Manufacturing Committee and Srikanth Patala of the Computational Materials Science and Engineering Committee provided useful discussions in the development and co-sponsorship of this special topic.

(Received September 1, 2020; accepted September 9, 2020; published online September 30, 2020) understanding of the slag blast status in real time. As a result of the rapid advancement of sensors and detectors, steel companies have accumulated a large amount of production data during long-term operation. A ML methodology was developed to use such data to provide the $\mathrm{BF}$ slag viscosity information in real time.

"Assessment of Cutting Forces and Temperature in Tapered Milling of Stone-Plastic Composite using Response Surface Methodology" by Zhu et al. investigates the milling performance of a new engineering material as a replacement for traditional materials used in furniture, packaging, and flooring, due to its durability, wear resistance, and environmental friendliness. The machinability of stone-plastic composite (SPC) materials during the tapered milling process, mainly focusing on the influence of cutting parameters on the cutting force and temperature, was analyzed using a response surface methodology for varied angle geometries and cutting parameters during tapered milling of the SPC with polycrystalline diamond cutters. Information is given about the material properties of SPC, planing performance, and problems encountered during SPC machining. It is proposed that these parameters be adopted in industrial machining for higher machining efficiency and lower production cost.

Useful models to predict the resultant microstructure and hardness allow for the optimization of welding process parameters to achieve the best microstructure possible are explained in the article by Geng et al., "Prediction of Continuous Cooling Transformation Diagrams for Ni-Cr-Mo Welding Steels via Machine Learning Approaches." Continuous cooling transformation (CCT) diagrams in welding steels show transformation temperatures and metallographic changes of weld heat-affected zones during cooling. This information is useful to evaluate the weldability of steels and to guide the welding process since it is difficult to measure synthetic weld heat-affected zone (SH-CCT) 
diagrams by experiment. In this study, various machine-learning approaches are performed to predict SH-CCT diagrams of Ni-Cr-Mo steels using relevant material descriptors, including the chemical compositions and cooling rates.

"Predicting Tensile Properties of AZ31 Magnesium Alloys by Machine Learning" by Xu et al. is of particular interest to the automotive, aerospace, and biomedical industries, since magnesium alloys are used as structural materials due to their low density, high specific strength, and good biocompatibility. Mechanical properties of $\mathrm{Mg}$ wrought alloys depend on the chemical composition and the processing history, which control the microstructure, such as grain size, texture, and precipitates. AZ31 magnesium alloys from different suppliers can have different chemistries and processing histories, which affect the mechanical properties. This work uses machine learning to establish quantitative relationships between alloy compositions, processing parameters, and mechanical properties. Artificial neural networks and support vector machine algorithms were found to provide good accuracy in predicting yield strength, ultimate tensile strength, and tensile elongation.

These articles provide new insights and methods applicable to problems of interest relevant to our readers. The material presented here is appropriate for researchers, students, and practicing engineers in various materials and metallurgical fields.

The papers in this special topic, Machine Learning Applications in Advanced Manufacturing Processes, can be accessed via the November issue's Table of Contents page at https://link.springer.com/ journal/11837/72/11/page/1.

\section{CONFLICT OF INTEREST}

The author declares that there is no conflict of interest.

Publisher's Note Springer Nature remains neutral with regard to jurisdictional claims in published maps and institutional affiliations. 